\title{
Aconitase and Isocitric Dehydrogenases of Aspergillus niger in Relation to Citric Acid Production
}

\author{
By JULIA M. LA NAUZE* \\ School of Microbiology, University of Melbourne, Victoria, Australia
}

(Received 16 November 1965)

\begin{abstract}
SUMMARY
Aconitase and NAD- and NADP-linked isocitric dehydrogenases were examined in two strains of Aspergillus niger. The mutant strain 72-44 produced higher yields of citric acid on the culture medium used than did the parent strain 72-4. After growth for $22 \mathrm{hr}$ on a medium in which citric acid did not accumulate, the amounts of each enzyme in the parent strain were approximately the same as those in the mutant strain. The enzymes were also found, though in lower amounts, throughout the incubation period of 8 days in both strains grown on a medium in which citric acid accumulated. A 20-fold increase in the concentration of iron in this medium doubled the activity of aconitase in extracts from the mutant strain, though citric acid accumulation was only decreased by $25 \%$. The addition of monofluoroacetate to the culture medium was toxic to the mould and did not stimulate citric acid yields. It is suggested that during the incubation, some recycling of citric acid may take place. The difference in citric acid yields from the parent and mutant strains was not accounted for on the basis of the degrees of aconitase or isocitric dehydrogenase activity.
\end{abstract}

\section{INTRODUCTION}

Under certain conditions of nutritional deficiency strains of Aspergillus niger are capable of excreting large quantities of citric acid (Perlman \& Sih, 1960). Cleland \& Johnson (1954), by using glucose-3,4-14 C obtained results which suggested a scheme for the formation of citrate from glucose The distribution of radioactivity in the citrate indicated that there was little recycling of the acid. Ramakrishnan, Steel \& Lentz (1955) implied that accumulation of citric acid resulted from a deficiency in the tricarboxylic acid cycle enzymes aconitase and isocitric dehydrogenase. In a culture which yielded $7 \cdot 1 \mathrm{~g}$. anhydrous citric acid/100 ml. culture fluid, they were unable to detect the two enzymes in extracts prepared after citric acid accumulation had begun. Since strains of $A$. niger differ in their ability to accumulate citric acid they might, on the above hypothesis, be expected to contain different quantities of some enzymes of the tricarboxylic acid cycle. In the present study, two strains of $A$. niger were used. The mutant strain $72-44$, which is characterized by restricted growth and delayed sporulation, was derived from the parent strain 72-4 after ultraviolet irradiation; it produces higher yields of citric acid than does the parent on the particular medium used. This paper describes an investigation of aconitase and isocitric dehydrogenase in the two strains of $A$. niger when grown,

* Present address: Biochemistry Department, John Curtin School of Medical Research, Australian National University, Canberra, Australia. 
first, on a medium which favoured growth rather than citric acid production, and secondly on a metal-deficient medium which allowed citric acid to accumulate.

\section{METHODS}

Organisms. Aspergillus niger Wisconsin strain 72-4, ATcc 11414 (Perlman, Kita \& Peterson, 1946), will be referred to as the parent strain. The mutant strain 72-44 was derived by Millis, Trumpy \& Palmer (1963) from the parent after ultraviolet irradiation. Stock cultures were maintained as lyophilized spores and working cultures were grown on beer-wort agar slopes. The parent organism spored readily on beer-wort slopes in $\mathbf{3}$ days, whereas the mutant required 10 days to produce an adequate degree of sporulation.

\section{Cultures on fluid media}

Glucose malt-extract yeast medium (GMY). This medium was used for the production of mycelium for enzyme extracts under conditions where citric acid did not accumulate. It was essentially that used by Martin (1954) and consisted of $1 \%$ glucose, $3 \%$ malt extract, and $0.5 \%$ yeast extract dispensed in $100 \mathrm{ml}$. volumes in $500 \mathrm{ml}$. Erlenmeyer flasks which were autoclaved at $116^{\circ}$ for $10 \mathrm{~min}$.

Fermentation medium (Medium $\boldsymbol{B}$ ). This medium developed by Millis, Trumpy \& Palmer (1963) was used for studies under conditions for citric acid accumulation. It consisted of a $14 \%(\mathrm{w} / \mathrm{v})$ solution of sucrose (A1 grade commercial cane sugar, Colonia iS'igar Refineries, Australia) which was passed through a cation exchange resin Zeocarb 215 (Permutit Co.) in the $\mathrm{H}^{+}$form. To this were added (g./l.): $\mathrm{MgSO}_{4} .7 \mathrm{H}_{2} \mathrm{O}, 0 \cdot 15 ; \mathrm{KH}_{2} \mathrm{PO}_{4}, 0 \cdot 30 ; \mathrm{NH}_{4} \mathrm{NO}_{3}, 1 \cdot 4 ;(\mathrm{mg} . / \mathrm{l}):. \mathrm{Cu}^{2+}, 0 \cdot 3 ; \mathrm{Fe}^{2+}, 2 \cdot 0$; and $\mathrm{Zn}^{2+}, 0 \cdot 1$. The medium was dispensed in $50 \mathrm{ml}$. volumes in $500 \mathrm{ml}$. acid-washed flasks and autoclaved at $116^{\circ}$ for $10 \mathrm{~min}$.

Inoculation of flasks. Spores from a beer-wort agar slope were suspended in $1 / 10,000(w / v)$ sterile 'Soaxit' (sodium dioctyl-sulphosuccinate; W. Hermon Slade Co., Homebush, N.S.W.). The suspension was shaken vigorously to disperse clumps and the spores counted in a haemocytometer. These were then added to the flasks at the rate of $1 \times 10^{8}$ spores $/ 50 \mathrm{ml}$. medium.

Conditions of incubation. The flasks were incubated at $30^{\circ}$ on a shaker which was rotated at $210 \mathrm{rev} . / \mathrm{min}$. with a $2 \mathrm{in}$. amplitude throw. The flasks were placed at an angle of $15^{\circ}$ to the horizontal to improve aeration. Cultures on GMY medium were incubated for $22 \mathrm{hr}$ and those on medium $\mathrm{B}$ for various times up to 8 days.

\section{Analysis of cultures}

Mould growth. The wet weight of mycelium was used as a rough index of growth. The contents of each flask were filtered through a Buchner funnel with Whatman paper no. 541, washed with ice-cold water, sucked until damp dry, and weighed to the nearest $0 \cdot 1 \mathrm{~g}$. This mycelium was used for the preparation of enzyme extracts.

Citric acid. The fermentation liquor was separated from the mycelium by filtration through a Buchner funnel with Whatman paper no. 541. The filtrate + washings were made up to $100 \mathrm{ml}$. and the yield of citric acid was measured by titrating a $4 \mathrm{ml}$. sample against 0.25 $\mathrm{M}-\mathrm{NaOH}$ (Millis, Trumpy \& Palmer, 1963). The results were expressed as $\mathrm{g}$. anhydrous citric acid/100 ml. original culture fluid. 
Sugar utilized. The colorimetric method developed by Somogyi (1952) was used for estimating residual sugar. Samples were diluted to contain between 25 and 600 sugar reducing $\mu \mathrm{g} . / \mathrm{ml}$. and sucrose was hydrolysed by heating $1 \mathrm{ml}$. at $100^{\circ}$ for 10 min. with $0.1 \mathrm{ml}$. $0.5 \mathrm{M}_{-} \mathrm{H}_{2} \mathrm{SO}_{4}$. On cooling, $0.1 \mathrm{ml}$. $\mathrm{M}-\mathrm{NaOH}$ was added to neutralize the sulphuric acid before proceeding with the estimation.

\section{Preparation of enzyme extracts}

Mycelium from GMY medium was washed with ice-cold water, filtered through four layers of gauze and pressed dry. It was then weighed to the nearest $0 \cdot 1 \mathrm{~g}$., and placed in a Petri dish in ice until used.

Mycelium from medium B was filtered on a Buchner funnel with Whatman paper no. 541, and washed with ice-cold water. The mycelial pad was weighed to the nearest $\mathbf{0} \cdot \mathbf{1}$ g. and resuspended in ice-cold water. To neutralize the citric acid, $\mathbf{M}-\mathrm{KOH}$ was added dropwise to the mixture, with use of a magnetic stirrer, until it remained at pH $7 \cdot 2$ to $7 \cdot 4$. The mycelium was then refiltered and kept in ice until used.

Water was used for the preparation of extracts containing aconitase from mycelium grown on GMY medium, and $0 \cdot 1 \mathrm{M}$-borate buffer $(\mathrm{pH} \mathrm{7.5)}$ was used for mycelium grown on medium B. For NAD- and NADP-linked isocitric dehydrogenases, $\mathbf{0} \cdot \mathbf{1} \mathrm{M}$-potassium phosphate buffer $\left(\mathrm{pH} 7 \cdot 0\right.$ ), containing $10^{-3} \mathrm{M}$ glutathione (freshly prepared) was used in both cases. The washed mycelium was placed in a 7-inch porcelain mortar cooled in an ice bath and ground for 5 min. with an equal weight of cold washed 600 crystal Corundum. Three times the volume of cold extraction fluid was then added and the mycelium ground for a further $5 \mathrm{~min}$. The temperature was kept below $4^{\circ}$ throughout the operation. The extract was centrifuged at $500 \mathrm{~g}$ for $10 \mathrm{~min}$. at $0^{\circ}$ to remove the bulk of the Corundum and cellular debris, and it was then centrifuged at $21,600 \mathrm{~g}$ for $15 \mathrm{~min}$. at $0^{\circ}$ and the supernatant fluid assayed for enzyme activity.

Extracts of mycelium grown on medium B were treated with protamine sulphate to remove material which absorbed at $260 \mathrm{~m} \mu$, and thus interfered with the assay of aconitase. After adding a fifth of its volume of a $1 \%$ solution of protamine sulphate the extract was stirred for $15 \mathrm{~min}$. with a magnetic stirrer, then centrifuged at $4600 \mathrm{~g}$ for $10 \mathrm{~min}$. The precipitate was discarded and the supernatant fluid assayed for enzyme activity.

Protein was estimated by the method of Lowry, Rosebrough, Farr \& Randall (1951) and expressed as $\mathrm{mg} . / \mathrm{ml}$.

\section{Enzyme assays}

Spectrophotometric measurements were made with a Unicam Spectrophotometer (S.P. 500) with a temperature control unit (S.P. 570) holding two 1-cm. cuvettes of $3 \mathrm{ml}$. capacity. Tests were made at $30^{\circ}$, a period of $5 \mathrm{~min}$. being allowed before the addition of substrate, to enable the temperature of the test system in the cuvettes to reach that of the water bath.

The unit of activity was defined as an initial rate of increase in extinction of $0.001 / \mathrm{min} . / \mathrm{ml}$. extract. Specific activity was expressed as units $/ \mathrm{mg}$. protein.

Aconitase. The activity of this enzyme was determined by measuring the rate of appearance of cis-aconitate at $240 \mathrm{~m} \mu$ from either citrate or isocitrate according to the method of Racker (1950). To a Unicam cuvette were added: 0.2 M-sodium 
citrate, $0.3 \mathrm{ml}$, or $0.1 \mathrm{M}$-sodium isocitrate, $0.4 \mathrm{ml}$., each in $0.05 \mathrm{~m}$-potassium

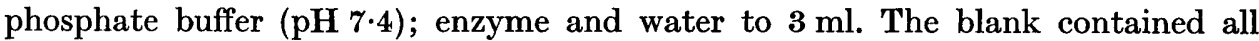
components other than substrate. The increase in extinction was measured at $1 \mathrm{~min}$. intervals for $5 \mathrm{~min}$.

$N A D$-linked isocitric dehydrogenase. This enzyme was assayed by measuring the increase in extinction at $340 \mathrm{~m} \mu$ resulting from the reduction of NAD, according to the method of Ochoa (1948). To a Unicam cuvette were added: 0.5 M-potassium phosphate buffer (pH 7.0), 0.2 ml.; 0.005 м-NAD, 0.3 ml.; 0.0025 M-AMP, 0.3 ml.;

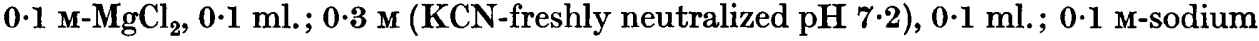
isocitrate, $0.1 \mathrm{ml}$; enzyme and water to $3 \mathrm{ml}$. A blank containing all comporients other than substrate was used in each assay. The increase in extinction at $340 \mathrm{~m} \mu$ was measured at 30 sec. intervals for $3 \mathrm{~min}$. $\mathrm{KCN}$ was included in the assay system because the enzyme preparations contained substances capable of oxidizing the reduced NAD.

NADP-linked isocitric dehydrogenase. The activity of this isocitric dehydrogenase was also determined at $340 \mathrm{~m} \mu$. To a Unicam cuvette were added: $0.5 \mathrm{M}$-potassium phosphate buffer (pH 7.4), 0.2 ml.; 0.0025 M-NADP, 0.3 ml.; 0.1 M- $\mathrm{MgCl}_{2}, 0.1 \mathrm{ml}$;

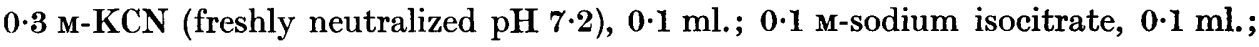
enzyme and water to $3 \mathrm{ml}$. A blank containing all components other than substrate was used in each assay. The increase in extinction at $340 \mathrm{~m} \mu$ was measured at 30second intervals for $3 \mathrm{~min}$.

\section{RESULTS}

\section{Cultural characteristics}

The mutant strain Aspergillus niger 72-44 was easily distinguished from the parent strain by its restricted colony development and delayed sporulation on agar media. In GMY liquid medium, it grew at a slightly slower rate than the parent and usually formed discrete pellets about $1 \mathrm{~mm}$. in diameter, whereas the parent formed a mass of loose filamentous growth throughout the medium.

On medium B, the mutant produced a higher yield of citric acid than the parent, generally in the range of $8-10 \mathrm{~g} . / 100 \mathrm{ml}$. (see Trumpy \& Millis, 1963) while the yield with the parent was 2-3 g. citric acid/100 ml. Cultures were analysed for the amount of sugar utilized and for weight of mycelium formed. The course of a typical fermentation is shown in Fig. 1.

\section{Enzymic studies under conditions when citric acid did not accumulate}

The activity of aconitase in each organism was determined on two occasions after growth for $22 \mathrm{hr}$ in GMY medium. The rate of the reaction citrate $\rightarrow$ cis-aconitate was about half that of the reaction isocitrate $\rightarrow$ cis-aconitate. Although the amounts of enzyme differed in the two experiments the same ratio of reaction rates was obtained with both strains of Aspergillus. This suggests that the strains do not differ greatly in the activity of aconitase or aconitic hydrase. The latter enzyme, demonstrated in extracts of Aspergillus niger by Neilson (1956), catalyses the reaction citrate $\rightarrow$ cis-aconitate only. The results are shown in Table 1.

The amount of both isocitric dehydrogenases in the two organisms was determined under the same conditions in three separate experiments (see Table 2). Since 


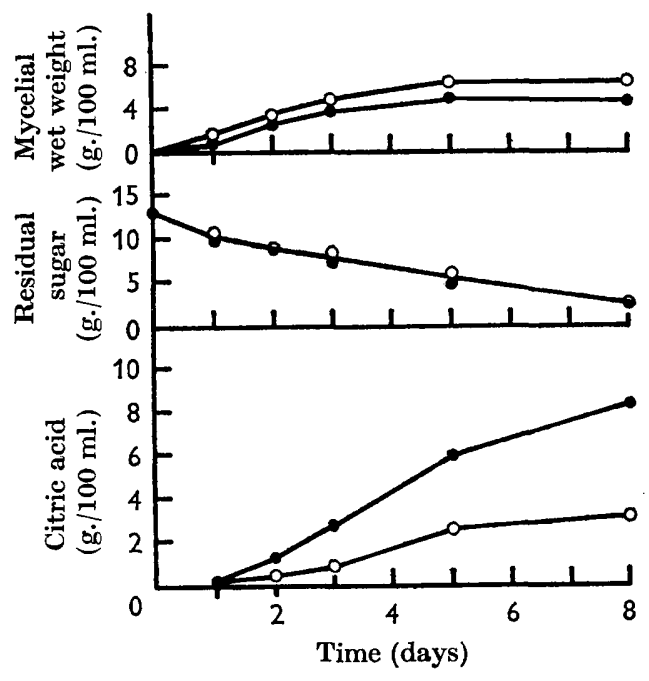

Fig. 1

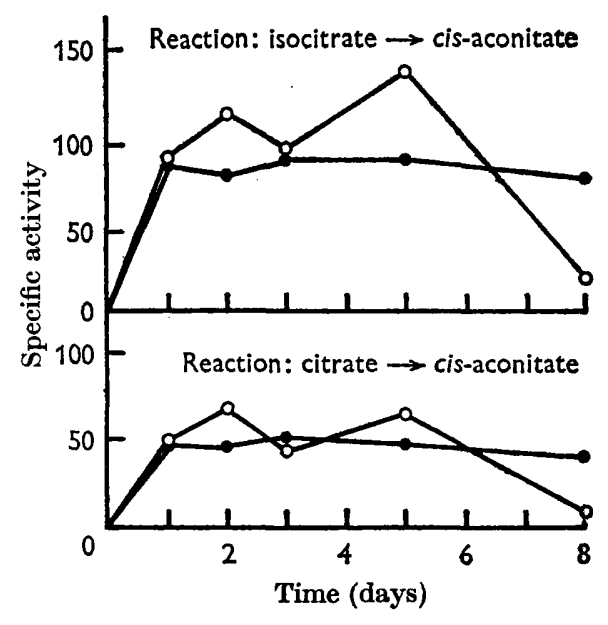

Fig. 2

Fig. 1. Rates of growth, sugar utilization and citric acid production on medium $\mathbf{B}$ by Aspergillus niger strain 72-4 (O-O) and strain 72-44 (O-O).

Fig. 2. Specific activity of aconitase in Aspergillus niger strains during growth on medium $\mathrm{B}$; $\mathrm{O}-\mathrm{O}$ Aspergillus niger strain 72-4; - $A$. niger strain 72-44. Specific activity is expressed as enzyme units/mg. protein, one unit being defined as an initial rate of increase in extinction at $240 \mathrm{~m} \mu$ of $0.001 / \mathrm{min} . / \mathrm{ml}$. enzyme extract.

Table 1. Specific activity of aconitase in Aspergillus niger strains grown on GMY medium

\begin{tabular}{|c|c|c|c|}
\hline \multirow[b]{2}{*}{ Organism } & \multicolumn{2}{|c|}{ Specific activity* } & \multirow[b]{2}{*}{$\begin{array}{c}\text { Ratio } \\
\text { isocitrate } \\
\text { citrate }\end{array}$} \\
\hline & $\begin{array}{c}\text { Reaction } \\
\text { citrate } \rightarrow \\
\text { cis-aconitate }\end{array}$ & $\begin{array}{c}\text { Reaction } \\
\text { isocitrate } \rightarrow \\
\text { cis-aconitate }\end{array}$ & \\
\hline $\begin{array}{r}\text { Exp. } a \text { A. niger } 72-4 \\
\text { A. niger } 72-44\end{array}$ & $\begin{array}{l}150 \\
154\end{array}$ & $\begin{array}{l}326 \\
366\end{array}$ & $\begin{array}{l}2 \cdot 2 \\
2 \cdot 4\end{array}$ \\
\hline $\begin{array}{r}\text { Exp. } b \text { A. niger } 72-4 \\
A . \text { niger } 72-44\end{array}$ & $\begin{array}{l}106 \\
117\end{array}$ & $\begin{array}{l}207 \\
238\end{array}$ & $\begin{array}{l}2 \cdot 0 \\
2 \cdot 1\end{array}$ \\
\hline
\end{tabular}

* Specific activity is expressed as enzyme units/mg. protein, one unit being defined as an initial rate of increase in extinction at $240 \mathrm{~m} \mu$ of $0.001 / \mathrm{min} . / \mathrm{ml}$. enzyme extract.

there was variation in the specific activities obtained, it is not possible to conclude whether or not there is any significant difference between the two organisms in this respect. Experiment $(c)$ showed similar values in the two organisms, suggesting that the differences found in experiments $(a)$ and $(b)$ were not significant.

\section{Enzymic studies under conditions of citric acid accumulation}

Twenty flasks of medium B were inoculated with the parent organism and a similar number with the mutant strain 72-44. Sufficient amounts of material to yield 2 to $4 \mathrm{~g}$. wet wt. mycelium were harvested 1, 2, 3, 5 and 8 days after inoculation and the corresponding enzyme extracts were prepared. 
Mycelium which has accumulated citric acid contains some intracellular acid. Initially difficulty was experienced in obtaining active enzyme preparations through failure to keep the $\mathrm{pH}$ value of the extracts near to neutral. Active preparations were obtained by washing the mycelium with ice-cold water followed by the dropwise addition of $\mathrm{M}-\mathrm{KOH}$ to maintain at $\mathrm{pH} 7 \cdot 2$ to $7 \cdot 4$; an extract was then prepared in the usual manner and assayed.

Table 2. Specific activity of isocitric dehydrogenases in Aspergillus niger strains grown on GMY medium

\begin{tabular}{|c|c|c|}
\hline \multirow[b]{2}{*}{ Organism } & \multicolumn{2}{|c|}{ Specific activity* } \\
\hline & $\begin{array}{l}\text { NAD-linked } \\
\text { isocitric } \\
\text { dehydrogenase }\end{array}$ & $\begin{array}{l}\text { NADP-linked } \\
\text { isocitric } \\
\text { dehydrogenase }\end{array}$ \\
\hline $\begin{array}{c}\text { Exp. } a \text { A. niger } 72-4 \\
A . \text { niger } 72-44\end{array}$ & $\begin{array}{l}90 \\
51\end{array}$ & $\begin{array}{l}35 \\
22\end{array}$ \\
\hline $\begin{array}{r}\text { Exp. } b \text { A. niger } 72-4 \\
A . \text { niger } 72-44\end{array}$ & $\begin{array}{l}37 \\
\mathbf{2 2}\end{array}$ & $\begin{array}{l}26 \\
12\end{array}$ \\
\hline $\begin{array}{c}\text { Exp. } c \text { A. niger 72-4 } \\
\text { A. niger 72-44 }\end{array}$ & $\begin{array}{l}42 \\
35\end{array}$ & $\begin{array}{l}21 \\
19\end{array}$ \\
\hline
\end{tabular}

* Specific activity is expressed as enzyme units/mg. protein, one unit being defined as an initial rate of increase in extinction at $340 \mathrm{~m} \mu$ of $0.001 / \mathrm{min}$. $/ \mathrm{ml}$. enzyme extract.

Aconitase and both isocitric dehydrogenases were present during the entire incubation period. The activity of aconitase was about the same in the parent organism as in the mutant (see Fig. 2). The reactions citrate $\rightarrow$ cis-aconitate and isocitrate $\rightarrow c i s$-aconitate were again measured and there was little change in their ratio. The specific activity of aconitase during growth on medium $B$ was about onethird of that found after $22 \mathrm{hr}$ incubation on GMY medium.

The mutant appeared to have slightly higher values of both isocitric dehydrogenases than had the parent (see Fig. 3), but this difference may not be significant. The decrease in activity on the 5th day was unexplained, possibly some denaturation of enzymes took place during preparation of the extracts.

\section{The influence of iron on aconitase activity}

Some workers have reported that ferrous ions activate purified preparations of aconitase from mammalian tissues (Dickman \& Cloutier, 1950, 1951; Morrison, 1954). By using Morrison's methods in the present work it was found that, when precipitated with ammonium sulphate and dialysed, the partially purified aconitase of Aspergillus niger could be activated 4-fold by adding iron and cysteine. Since iron is one of the metals which must be restricted to very low concentrations in the medium in order to obtain high citric acid yields, the relation between iron, aconitase activity and citric acid yield was investigated.

Aspergillus niger 72-44 was inoculated into medium $\mathrm{B}\left(\mathrm{Fe}^{2+}, 2 \cdot 0 \mathrm{mg} . / \mathrm{l}\right.$.) and into the same medium supplemented with iron $\left(\mathrm{Fe}^{2+}, 40 \mathrm{mg}\right.$./. .) Samples of mycelium were harvested 1, 2, 3, 5 and 8 days after inoculation. Each sample was analysed for the amount of organism, sugar utilized and citric acid yield (see Fig. 4). The presence of additional iron enhanced growth, causing the mould to form larger pellets. The 
yield of citric acid decreased by about $25 \%$, but there was no significant difference in the rates of sugar utilization. Aconitase values were about doubled (see Fig. 5), but the yield of citric acid was still high. Again, there was little change in the ratios of the two reactions catalysed by aconitase.

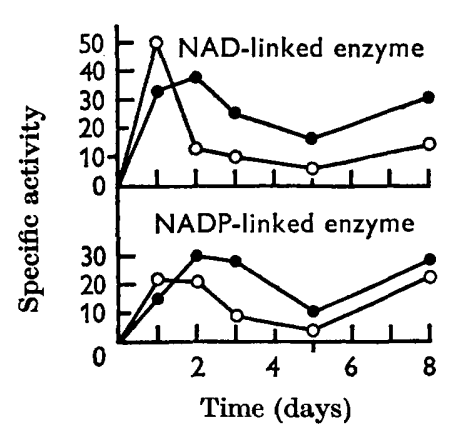

Fig. 3

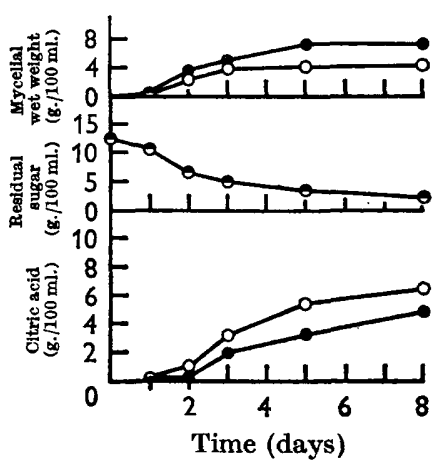

Fig. 4

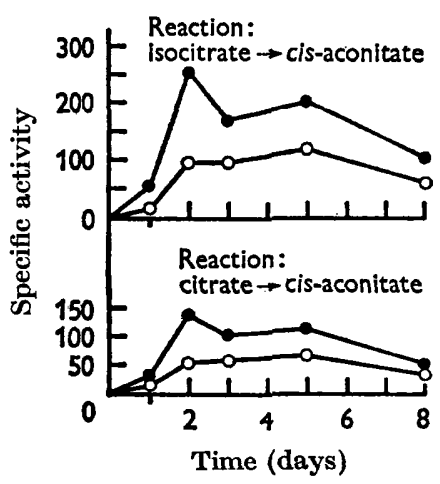

Fig. 5

Fig. 3. Specific activity of NAD-linked and NADP-linked isocitric dehydrogenases in Aspergillus niger strains during citric acid accumulation on medium $\mathrm{B}$; $\mathrm{O}-\mathrm{O} \boldsymbol{A}$. niger strain 72-4; - $A$. niger strain 72-44. Specific activity is expressed as units/mg. protein, one unit being defined as an initial rate of increase in extinction at $340 \mathrm{~m} \mu$ of $0 \cdot 001 / \mathrm{min}$./ml. enzyme extract.

Fig. 4. Rates of growth, sugar utilization and citric acid production by Aspergillus niger strain 72-44 on medium $B$ containing different concentrations of iron; $\mathrm{O}-\mathrm{O} \mathrm{Fe}^{2+2} \cdot 0 \mathrm{mg} . / \mathrm{l} .-\mathrm{Fe}^{2+} 40 \mathrm{mg} . / \mathrm{l}$.

Fig. 5. Specific activity of aconitase in Aspergillus niger strain 72-44 during growth in

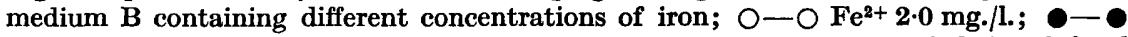
$\mathrm{Fe}^{2+} 40 \mathrm{mg}$./l. Specific activity is expressed as units/mg. protein, one unit being defined as an initial rate of increase in extinction at $240 \mathrm{~m} \mu$ of $0.001 / \mathrm{min} . / \mathrm{ml}$. enzyme extract.

\section{Effect of fluoroacetate on citric acid yield}

Fluoroacetate is converted in mammalian tissues to fluorocitrate which is a potent inhibitor of aconitase (Morrison \& Peters, 1954). The effect of fluoroacetate on both the parent and mutant Aspergillus niger strains was examined under conditions for citric acid accumulation to see whether the yields could be increased by the inhibition of aconitase. Fluoroacetate is most effective when present in the undissociated form (Aldous \& Rozee, 1956). The $\mathrm{pH}$ value of medium B during growth of $A$. niger varied from $\mathrm{pH} 3 \cdot 5$ to $2 \cdot 0$, so that fluoroacetate would be present largely in the undissociated form. Sodium monofluoroacetate was added at the rate of $20 \mu$ moles and $200 \mu$ moles/flask at various stages during the incubation of $\boldsymbol{A}$. niger cultures. At the end of the period, 8 days after inoculation, the flasks were analysed for yield of organism and citric acid, and for sugar utilization. Fluoroacetate depressed the yield of organism and of citric acid and the sugar utilization in both organisms. 


\section{DISCUSSION}

The present investigation was done with the object of detecting differences in enzymic constitution as between the parent and mutant strains of Aspergillus niger which might indicate why the mutant strain produces higher yields of citric acid on the medium used. Previous enzymic studies of $\boldsymbol{A}$. niger had indicated that, from the time when citric acid began to accumulate, aconitase and isocitric dehydrogenase were not present (Ramakrishnan et al. 1955). However, in that work it was not stated which isocitric dehydrogenase was examined. In the present work, aconitase and both the NAD-linked and the NADP-linked isocitric dehydrogenases were studied. No difficulty was experienced in obtaining active preparations of these enzymes from mycelium grown on a medium which favoured growth rather than citric acid accumulation. Provided that precautions were taken to maintain the $\mathrm{pH}$ value near neutrality during preparation of the extracts, the enzymes were also found throughout the incubation period of 8 days in both strains grown on a citric acid accumulation medium, a result in contrast to that of Ramakrishnan et al. These workers gave no details of the preparation of their extracts, nor did they mention precautions to avoid denaturation during preparation. It seems possible that inactivation of the enzymes could account for their results.

In Aspergillus niger the increased yields of citric acid at lowered metal concentrations may result from diminution in synthesis of the enzymes or restriction of their activity, for example, through lack of a metal co-factor. Iron is known to be required for maximal activity of aconitase from mammalian sources and is one of the critical metals involved in citric acid accumulation. Since it might influence accumulation by restriction of the activity of aconitase, the relation between iron and aconitase was examined. The addition to the culture medium of twenty times the optimal concentration for citric acid accumulation by $A$. niger 72-44, roughly doubled the amount of aconitase activity in that organism. Nevertheless, citric acid production was still quite high, being about three-quarters of that formed in the control culture. The addition of monofluoroacetate to the culture medium did not stimulate citric acid yield though it markedly inhibited the growth of the organism. Its toxic effect may have resulted from interference with reactions not involving aconitase (see Elsden \& Ormerod, 1956; Callely \& Dagley, 1959).

There was no significant difference in the amounts of aconitase or of the isocitric dehydrogenases in the two strains of Aspergillus niger grown in a medium in which citric acid did not accumulate. These enzymes were also found, though at lower concentrations, in the two organisms throughout fermentation. Thus, it is possible that the tricarboxylic acid cycle may function during fermentation, although the work of Cleland \& Johnson (1954) indicated that there was little re-cycling of citric acid. The investigation did not reveal any significant differences in the quantities of these enzymes in the two strains of $\boldsymbol{A}$. niger which might account for the observed difference in their ability to accumulate citric acid.

I am grateful to Dr Joan F. Gardner and Dr Nancy F. Millis for advice and encouragement throughout the course of this work. Financial support was provided by grants from the University of Melbourne Research Fund. 


\section{REFERENCES}

Aldous, J. G. \& Rozee, K. R. (1956). The effect of pH on the toxicity of fluoroacetic acid. Biochem. J. 62, 605.

Callely, A. G. \& Dagley, S. (1959). A possible lethal synthesis of monofluoromalate. Biochim. biophys. Acta, 35, 256.

Cleland, W. W. \& Johnson, M. J. (1954). Tracer experiments on the mechanism of citric acid formation by Aspergillus niger. J. biol. Chem. 208, 679.

Dickman, S. R. \& Cloutier, A. A. (1950). Activation and stabilization of aconitase by ferrous ions. Arch. Biochem. Biophys. 25, 229.

Dickman, S. R. \& Cloutier, A. A. (1951). Factors affecting the activity of aconitase. J. biol. Chem. 188, 379.

ElsDen, S. R. \& Ormerod, J. G. (1956). The effect of monofluoroacetate on the metabolism of Rhodospirillum rubrum. Biochem. J. 63, 691.

Lowry, O. H., Rosebrough, N. J., Farr, A. L. \& Randall, R. J. (1951). Protein measurement with the Folin phenol reagent. J. biol. Chem. 193, 265.

Martin, S. M. (1954). The succinoxidase system in Aspergillus niger. Can. J. Microbiol. $1,6$.

Millis, N. F., Trumpy, B. H. \& Palmer, B. M. (1963). The effect of lipids on citric acid production by an Aspergillus niger mutant. J. gen. Microbiol. 30, 365.

Morrison, J. F. (1954). The activation of aconitase by ferrous ions and reducing agents. Biochem. J. 58, 685.

Morrison, J. F. \& Peters, R. A. (1954). Biochemistry of fluoroacetate poisoning: the effect of fluorocitrate on purified aconitase. Biochem. J. 58, 473.

Neilson, N. E. (1956). The presence of aconitase and 'aconitic hydrase' in Aspergillus niger. J. Bact. 71, 356.

OchоA, S. (1948). Biosynthesis of tricarboxylic acids by carbon dioxide fixation. III. Enzymic mechanisms. J. biol. Chem. 174, 133.

Perlman, D. \& Sir, C. J. (1960). Fungal synthesis of citric, fumaric and aconitic acids. Prog. ind. Microbiol. 2, 169.

Perlman, D., Kita, D. A. \& Peterson, W. H. (1946). Production of citric acid from cane molasses. Arch. Biochem. 11, 123.

RACKER, E. (1950). Spectrophotometric measurement of the enzymatic formation of fumaric and cis-aconitic acids. Biochem. biophys. Acta, 4, 211.

Ramakrishnan, C. V., Steel, R. \& Lentz, C. P. (1955). Mechanism of citric acid formation and accumulation in Aspergillus niger. Arch. Biochem. Biophys. 55, 270.

Somogyi, M. (1952). Notes on sugar determination. J. biol. Chem. 195, 19.

Trumpy, B. H. \& Millis, N. F. (1963). Nutritional requirements of an Aspergillus niger mutant for citric acid production. J. gen. Microbiol. 30, 381. 